\title{
Design of JT-60SA Magnets and Associated Experimental Validations
}

\author{
L. Zani, P. Barabaschi, D. Duglue, L. Meunier, M. Peyrot, V. Tomarchio, M. Verrecchia, P. Decool,
} J.-L. Marechal, A. Torre, A. Cucchiaro, A. della Corte, A. Di Zenobio, L. Muzzi, S. Turtù, S. Ishida, K. Yoshida, K. Tsuchiya, K. Kizu, and H. Murakami

\begin{abstract}
In the framework of the JT-60SA project, aiming at upgrading the present JT-60U tokamak toward a fully superconducting configuration, the detailed design phase led to adopt for the three main magnet systems a brand new design. Europe (EU) is expected to provide to Japan (JA) the totality of the toroidal field (TF) magnet system, while JA will provide both Equilibrium field (EF) and Central Solenoid (CS) systems. All magnet designs were optimized trough the past years and entered in parallel into extensive experimentally-based phases of concept validation, which came to maturation in the years 2009 and 2010 . For this, all magnet systems were investigated by mean of dedicated samples, e.g. conductor and joint samples designed, manufactured and tested at full scale in ad hoc facilities either in EU or in JA. The present paper, after an overall description of magnet systems layouts, presents in a general approach the different experimental campaigns dedicated to qualification design and manufacture processes of either coils, conductors and electrical joints. The main results with the associated analyses are shown and the main conclusions presented, especially regarding their contribution to consolidate the triggering of magnet mass production. The status of respective manufacturing stages in EU and in JA are also evoked.
\end{abstract}

Index Terms-Fusion, JT-60SA, superconducting magnets, tokamak.

\section{INTRODUCTION}

$\mathbf{T}$ HE project JT-60 Super Advanced (JT-60SA), aiming at operating in Japan is a new generation tokamak with two main objectives [1]: first, standing as an early fusion satellite installation able to consolidate the technological and scientific bases of the International Thermonuclear Experimental Reactor (ITER) program and second, aiming a central contribution to draw the main guidelines for DEMO which is the next step in fusion development roadmap. In this goal, the actual tokamak JT-60U, located in Naka (JA) is foreseen to be upgraded to the

Manuscript received August 01, 2010; accepted October 24, 2010.

L. Zani, P. Barabaschi, M. Peyrot, L. Meunier, V. Tomarchio and D. Duglue are with JT-60SA EU Home Team, Fusion for Energy, IPP Broader Fusion Development Department, 85748 Garching bei Munchen, Germany (e-mail: louis.zani@jt60sa.org).

P. Decool, A. Torre and J.-L. Marechal are with Association Euratom-CEA, CEA/DSM/DRFC, CEA Cadarache 13108 St Paul-Lez-Durance, France.

A. della Corte, A. Di Zenobio, L. Muzzi, A. Cucchiaro and S. Turtù are with ENEA, C.R. Frascati Superconductivity Laboratory, 00044 Frascati, Italy.

S. Ishida, K. Yoshida, K. Tsuchiya, K. Kizu and H. Murakami are with JT-60SA JA Home Team, Japan Atomic Energy Agency, Naka, Ibaraki, 311-0193, Japan.

Color versions of one or more of the figures in this paper are available online at http://ieeexplore.ieee.org.

Digital Object Identifier 10.1109/TASC.2010.2091235
TABLE I

JT-60SA MAIN PARAMETERS

\begin{tabular}{|c|c|c|}
\hline & ITER-shaped & Low aspect ratio \\
\hline Flat top duration (s) & \multicolumn{2}{|c|}{100} \\
\hline Plasma current (MA) & 3.5 & 5.5 \\
\hline Toroidal field (T) & 2.28 & 2.25 \\
\hline Major radius (m) & 2.93 & 2.97 \\
\hline Aspect ratio $\mathrm{A}$ & 2.6 & 2.5 \\
\hline Elongation $\mathrm{k}_{\mathrm{X}}$ & 1.8 & 1.93 \\
\hline Triangularity $\delta_{\mathrm{X}}$ & 0.43 & 0.53 \\
\hline Plasma $q_{95}$ & \multicolumn{2}{|c|}{$\sim 3$} \\
\hline $\begin{array}{l}\text { Plasma } n_{\mathrm{e}} / \mathrm{n}_{\text {Greenwald }} @ \\
\beta_{\mathrm{n}}=2.5\end{array}$ & 0.8 & $\sim 0.5$ \\
\hline Plasma volume $\left(\mathrm{m}^{3}\right)$ & 123 & 133 \\
\hline
\end{tabular}

JT-60SA configuration for which one of the most notable modification is a switch of magnet system from fully resistive to fully superconducting configuration.

The JT-60SA project is part of the EU-JA bilateral Broader Approach Agreement whose entry into force triggered extensive design and conception work on both parties sides from 2006 on. A particular effort was dedicated to superconducting magnets systems for their significant dominance in the overall budget and their critical aspect regarding the machine scientific scope. The procurement of superconducting system is shared between the two parties, EU and JA being respectively in charge of the TF magnet system and the Poloidal Field magnet system (which includes both EF and CS magnets).

The paper here presents an overview of the latest magnet systems layouts and their associated main design analyses, especially focusing on a description of the experimental basis that contributed to consolidate their design.

\section{GENERAL OVERVIEW}

The main scope of JT-60SA operation is to explore the steady-state plasma regimes in high-beta configurations. One central objective is to reach long-pulse duration domain with 100 seconds-long plasma shots. The reference scenarios include ITER-like configurations. The main relevant plasma parameters are shown in Table I.

The main upgraded components contributing to reach and sustain those extreme conditions are basically a 41 MW heating and current drive system, a target divertor able to withstand a 15 $\mathrm{MW} / \mathrm{m}^{2}$ heat flux and a fully superconducting magnet system with all its associated peripheral elements (cryogenic plant and power supplies). 


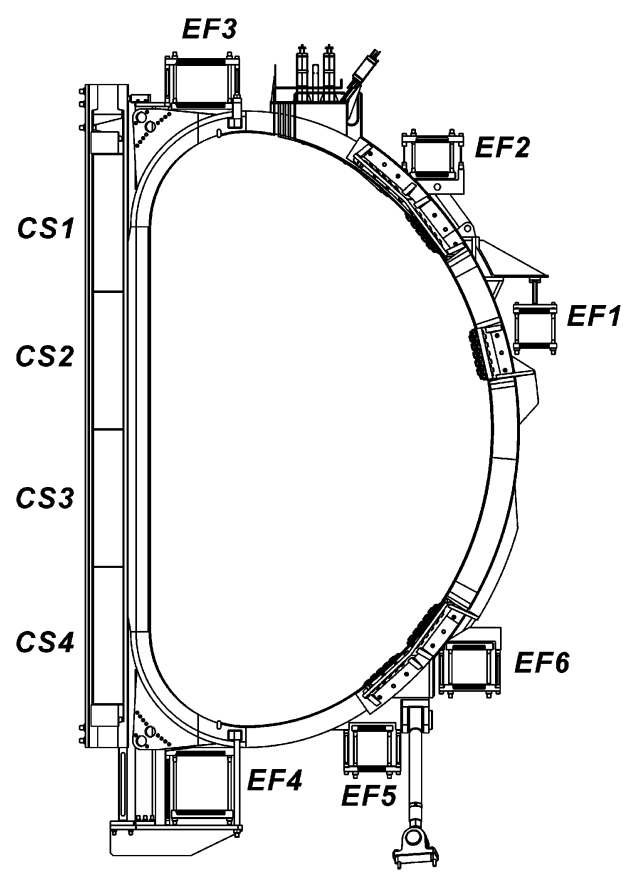

Fig. 1. Cross-section view of the JT-60SA TF, EF, and CS magnet systems. Corresponding attachment devices between the three systems are also visible.

Historically derived from National Centralized Tokamak (NCT) project [2]-[4] layout, the JT-60SA tokamak includes 18 TF coils, 6 EF coils and one CS coil subdivided in four stacked solenoids. A 2D view of the magnets arrangement in the tokomak can be seen in Fig. 1. The installation should operate 6000 shots in full operation and 12000 shots in reduced performances conditions. As magnets are among the tokamak components on which post-assembly intervention for sake of any operation optimization is extremely difficult, a particular attention was brought to safety margins approach all along their design phase.

Each magnet system was consequently designed combining numerical analyses and experimental approach throughout all the optimization process driven by the joint EU-JA team since 2006.

\section{TF MAGNET SySTEM}

The TF magnet system main function is to provide a magnetic field at plasma center to ensure plasma confinement. This magnet system performance being therefore central and possibly critical regarding the overall machine scope, therefore successive optimizations were led to reach the best compromise between risk and cost.

Initially including a design with mechanical structures similar as the one of ITER TF system and a conductor including strand of MRI-type (low superconductor ratio) [5], the concept was gradually optimized to match in the best conditions performances and cost [6].

At the price of minor modifications in the operation domain boundaries of the machine, the TF magnet reference operation conditions were further optimized by decreasing both TF Ampere-turns and maximum toroidal field, provided a compensation to recover plasma performance by an increase of the plasma volume [7]. The final TF operation conditions are shown in Table II.
TABLE II

JT-60SA TF Magnet System OPERATING PARAMETERS

\begin{tabular}{lc}
\hline \hline Magnetic energy (GJ) & $1.06 \mathrm{GJ}$ \\
Maximum field on conductor (T) & $5.65 \mathrm{~T}$ \\
Operating current (kA) & $25 \mathrm{kA}$ \\
Operating temperature $(\mathrm{K})$ & $\sim 4.8 \mathrm{~K}$ \\
TF system total weight $(\mathrm{t})$ & $\sim 370 \mathrm{t}$ \\
Mechanical structures total weight $(\mathrm{t})$ & $\sim 300 \mathrm{t}$ \\
Number of current lead pairs & 3 \\
Number of turn/coil & 72 \\
Number of pancake/coil & 6 (double pancakes) \\
Number of internal joints & 5 \\
Total internal joints resistance/coil $(\mathrm{n} \Omega)$ & 10 \\
Maximum ground voltage $(\mathrm{kV})$ & 1.4 \\
He mass flow rate/winding pack $(\mathrm{g} / \mathrm{s})$ & 48 \\
Conductor hydraulic length $(\mathrm{m})$ & 114 \\
\hline \hline
\end{tabular}

The $18 \mathrm{TF}$ coils are foreseen to be provided by Italy and France, respectively represented by ENEA and CEA institutes, that share the in-kind contribution, to be finally sent to Naka site for assembly under the responsibility of JAEA institute. The two main domains to ensure safe TF operating conditions have to do with mechanical and thermo-electric approaches. After information on general context, the latest updates and forthcoming activities on those domains are described below.

\section{A. Mechanical Approach}

The TF structures design combines classical tokamak guidelines and original concepts mainly applied for sake of cost and procurement organization. The winding packs are classically embedded in SS316 casings, wedged on the inner legs to sustain in-plane centripetal forces during operation. Conversely on the outer zone, an original system of separated Outer-Intercoil Structures (OIS) is used to sustain the out-of-plane forces while allowing the TF coils to radially expand, which relax constrains on gravity support design and facilitate procurement organization. A detailed description of the whole mechanical principles of TF system can be seen in [8], together with associated basic mechanical analyses [9].

Most recent detailed studies revealed a need to optimize the OIS design to increase its stiffness while maintaining a support to EF1 coil compatible with the general concept used so far (see EF section).

The main purpose was to ensure a proper space clearance to vertical ports by reducing the lateral TF strain due to out-of plane forces. An additional hanging articulated downward arm was fixed to the EF2 support, allowing to suppress the EF1 pedestals attached to the casing and its corresponding window in the OIS while reinforcement ribs were added to enhance the stiffness (see Fig. 2).

Slight updates of the TF system detailed design were implemented, validated by a global model mechanical analysis (to be presented soon). Design optimization are also ongoing on thermal shields arrangement and attachment concept.

Another delicate zone is the one dedicated to the electrical and cryogenic connections. The various components space allocation depends on many choices, such as technology for electrical joints, technology for voltage breakers, etc. 


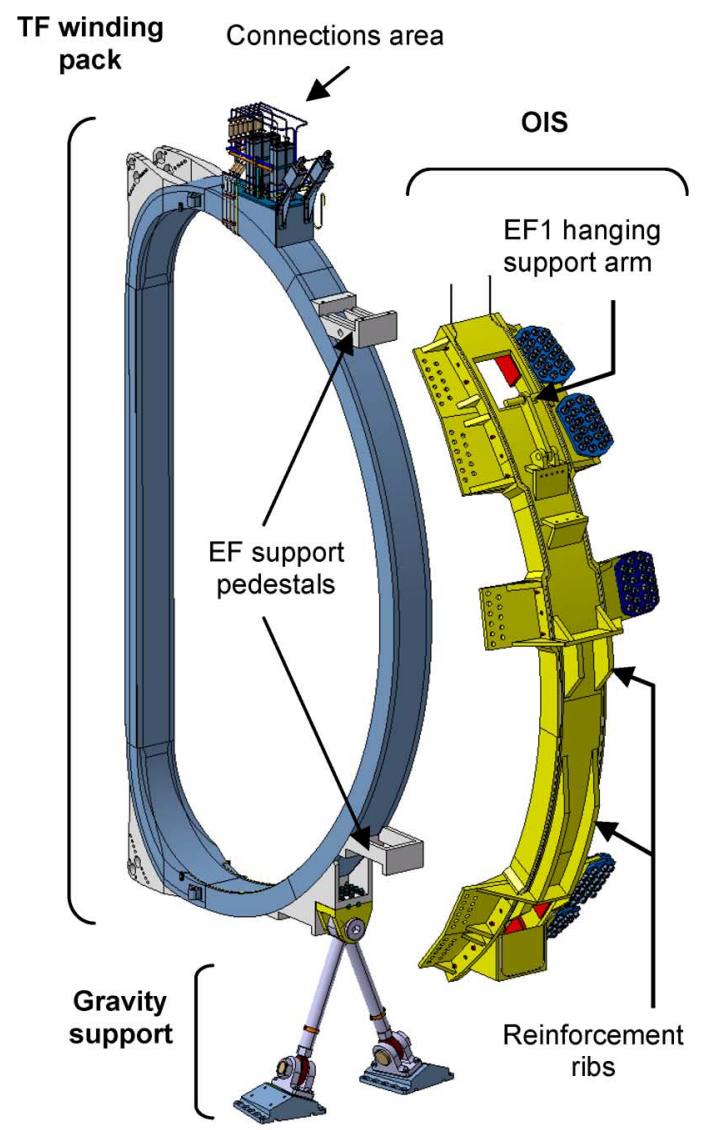

Fig. 2. 3D view of the TF coil updated design. The hanging support arm for EF1 is shown together with reinforcement flanges.

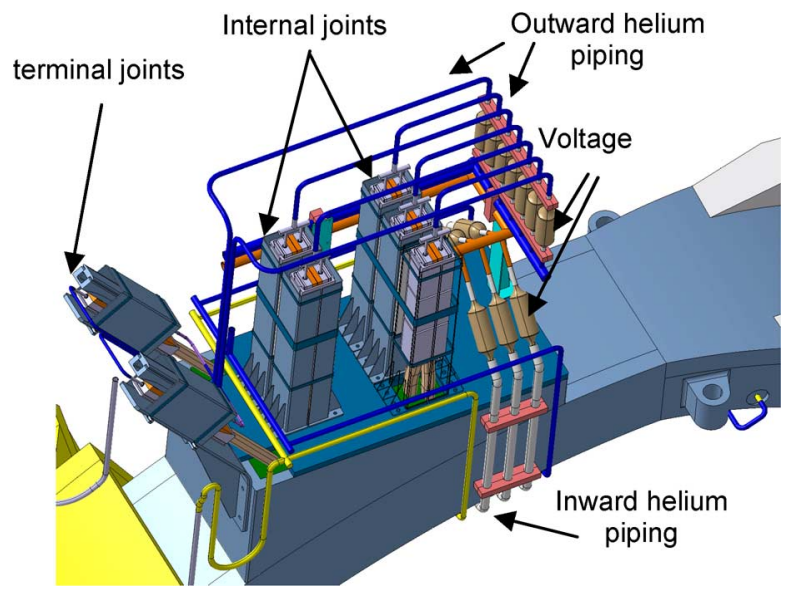

Fig. 3. 3D view of the connections area.

As far as electrical connections are concerned, an experimental approach was dedicated to them in order to ensure a safe approach on components that can be critical in the tokamak (see next section). Finally a reference arrangement for the joints in the connection area was set, preventing from clashes with other nearby components. Shown in Fig. 3, it actually stands as the latest baseline for further detailed optimizations.

An important structural component of the TF system is the gravity support (see Figs. 1 and 2), which concept is innovative. Optimized to withstand in major part the vertical stress, each support allows a complete freedom of the TF in the radial direction and rocking around a radial axis. The combination of all supports together brings proper stiffness to the complete TF coil system while allowing local displacements, thus relaxing the stress in the supports. The design foresees a stainless steel frame with $\mathrm{V}$-shaped supporting tube, connected to the TF coil and to the cryostat base by spherical plain bearings. This is the baseline of its providing degrees of freedom to TF coil. Due to its potential critical aspect, an experimental approach is foreseen to clear one issue: the major part of the gravity support components being procured under standard specifications to reduce economic and detailed design efforts, their industrial commissioning at too high temperature imposes to organize a proper qualification in cryogenic conditions. A dedicated experimental campaign should be held in 2011.

Another important structural component of the TF system is the helium inlet. Roughly located at each middle-length joggle of each TF double pancake, it interfaces the TF coil with cryoplant system. Its embedding in the casing stands it as a potential critical component, either for risk of leak or for causing of mass flow unbalance between pancakes or source of unacceptable pressure drop. In this framework, a first simple design was proposed by CEA [10] but confirming a high pressure drop. After further optimization it led to an ovale-shaped opening in the TF conductor jacket, with adapted welding interfaces to protect the conductor, reaching finally a better trade-off between feasibility and risk.

\section{B. Electromagnetic and Thermodynamic Approach}

For the TF conductor, both global and single-purpose experimental approaches were led, respectively associating connection or not in the sample design. A total of three samples relevant to the TF conductor features were produced and tested between 2008 and 2009. Detailed description of the samples designs, test program and the conclusions derived from experimental results are available in [11], [12]. The outcomes of experimental phase are synthesized below.

First, the TF conductor design was found sound with respect to the temperature safety margin when proper strand specifications are considerd. The main design parameters of conductor and strand can be seen in Table III, consolidated by previous electromagnetic and thermohydraulic studies [13]-[16] allowing to switch confidently to industrial phase. Recent parametric analyses have been led using common strand characteristics input for evaluating the possible critical performances degradations derived from TF coil manufacturing stages, e.g. casing-to-winding insulation tolerances (impacting heat flux from winding to conductor) or TF conductor compaction (inducing strong local strands deformation). As a result, it appeared that for sake of risk mitigation for the TF magnet system with respect to those possible causes of under-performance, it could be useful to consider TF strand specifications slightly more stringent $\left(0.1 \mathrm{~K}\right.$ to $0.2 \mathrm{~K}$ extra in $\mathrm{T}_{\mathrm{CS}}$ criterion) than the design features shown in Table III. The final decision will be made upon trade-off between risk considerations and financial approach.

Second, the twin-box type joint design is sound with respect to the total resistance criterion (see Table II), and shows for at least one strand layout option a minor influence on the conductor 
TABLE III

JT-60SA TF CONDUCTOR AND STRAND FEATURES

\begin{tabular}{|c|c|}
\hline \multicolumn{2}{|c|}{ STRAND } \\
\hline material type & $\mathrm{NbTi}$ \\
\hline Diameter (mm) & 0.81 \\
\hline Filament diameter $(\mu \mathrm{m})$ & $<25$ \\
\hline Filament twist pitch (mm) & 25 \\
\hline Non SC : SC ratio & $>1.3$ \\
\hline $\mathrm{I}_{\mathrm{C}}(4.2 \mathrm{~K}, 9.5 \mathrm{~T})(\mathrm{A})$ & $>60$ \\
\hline $\mathrm{T}_{\mathrm{CS}}(80 \mathrm{~A}, 5.65 \mathrm{~T})(\mathrm{K})$ & $>6.1$ \\
\hline Resistive barrier & internal $\mathrm{CuNi}$ or Ni plating \\
\hline $\mathrm{Q}_{\text {hyst }}\left(\mathrm{mJ} \cdot \mathrm{cm}^{-3}\right)$ & $<450$ \\
\hline RRR & $>80$ \\
\hline \multicolumn{2}{|c|}{ CONDUCTOR } \\
\hline Cable dimensions (mm) & $18 \times 22$ \\
\hline Wrapping & yes (external) \\
\hline Cable pattern & $(2 \mathrm{SC}+1 \mathrm{Cu}) \times 3 \times 3 \times 3 \times 6$ \\
\hline Twist pitch sequence & $45 / 70 / 120 / 190 / 290$ \\
\hline Jacket thickness (mm) & 2 \\
\hline Jacket material & modified $316 \mathrm{~L}$ \\
\hline Void fraction & $\sim 33 \%$ \\
\hline Cross-section & 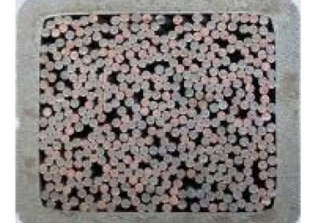 \\
\hline
\end{tabular}

TABLE IV

JT-60SA EF MAGNet System LAYOUt PARAMETERS

\begin{tabular}{|c|c|c|c|c|c|c|}
\hline & EF1 & EF2 & EF3 & EF4 & EF5 & EF6 \\
\hline Winding radius $(\mathrm{m})$ & 5.819 & 4.621 & \multicolumn{2}{|c|}{1.919} & 3.914 & 5.054 \\
\hline Number of turns & 142 & 154 & 247 & 353 & 152 & 180 \\
\hline Max. current (kA) & \multicolumn{6}{|c|}{20} \\
\hline Pancake type & \multicolumn{2}{|c|}{ single } & \multicolumn{2}{|c|}{ double } & \multicolumn{2}{|r|}{ single } \\
\hline Maximum field (T) & \multicolumn{2}{|c|}{4.8} & \multicolumn{2}{|c|}{6.2} & \multicolumn{2}{|c|}{4.8} \\
\hline Conduct. length (m) & 439 & 378 & \multicolumn{2}{|c|}{434} & 541 & 413 \\
\hline $\begin{array}{l}\text { Max. ground voltage } \\
(\mathrm{kV})\end{array}$ & \multicolumn{6}{|c|}{10} \\
\hline
\end{tabular}

critical parameters (T margin, transient stability). As a final outcome, the twin-box concept was experimentally validated [11] and was chosen to be the technology used for TF coils terminal joints. For internal joints, the design still let some options open and could also involve a second type of electrical connection investigated by ENEA [17]. Most recent activities addressed the optimization by CEA of the twin-box manufacturing process in JT-60SA configuration.

\section{EF MAGNET System}

The EF magnet system aims at generating transient poloidal field to provide plasma control. Six EF are foreseen to operate in JT-60SA, whose positions can be seen in Fig. 1. The main layout parameters of EF system can be seen in Table IV.

In its general principles, The $6 \mathrm{EF}$ magnets system is composed of conductor windings and external insulation layer, and are mechanically attached to the TF magnets by help of clamping systems bolted to TF casings dedicated pedestals

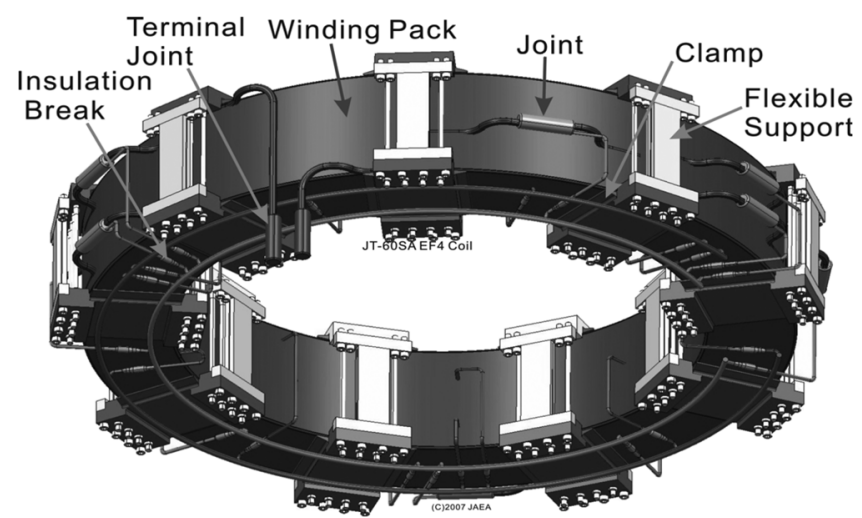

Fig. 4. 3D view of EF4 coil.

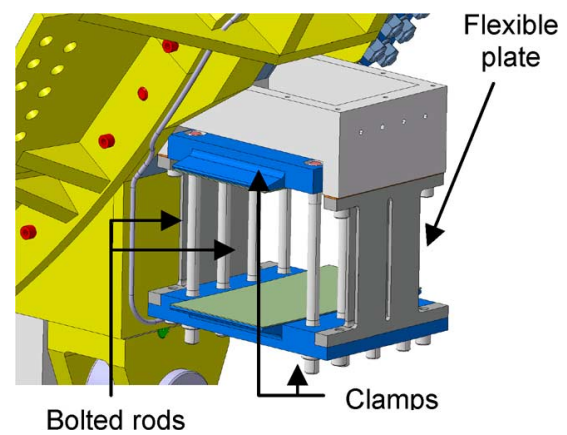

Fig. 5. 3D view of EF attachment support concept to TF magnets.

through flexible support plates. An overall illustration of EF4 coil system arrangement is shown in Fig. 4 and an example of the attachment structure to TF system is shown in Fig. 5.

\section{A. Mechanical Approach}

Extensive mechanical analyses were led on the system and on its interfaces with TF and CS system [18], [19], consolidating the general features of the actual design.

Still, a recent analysis was performed on the newly optimized TF-EF configuration with EF1 hanging system (see Fig. 1), showing mechanical safety margins by more than a factor of 2 versus classical membrane, membrane plus bending and total forces scenarios [20]. The actual concept is thus validated and stand as reference for further analyses.

On experimental ground, no specific tests are foreseen in the immediate future, but as those pulsed magnets have to sustain a lot of cycles dedicated fatigue tests can be envisaged, namely for the clamping system or for the helium inlet concept.

\section{B. Electromagnetic and Thermodynamic Approach}

As regard the experimental approach, extensive tests were led on dedicated samples either relevant to EF conductor or to the associated electrical connections. EF coils use two types of conductor, respectively referring to high $(\mathrm{EF}-\mathrm{H})$ or low (EF-L) operation peak field. The main parameters associated to EF conductor are shown in Table V. A central spiral ensures to remain within pressure drop limit ( $\sim 1$ bar), significantly overthrown otherwise, due to cooling lengths almost double. Same remark is valid for the CS (section below).

A first sample [21] tested in 2008 in NIFS facility [22] was in major areas relevant to the EF-H configuration, showing acceptable critical performances in operation-like conditions 
TABLE V

JT-60SA EF CONDUCTOR PARAMETERS

\begin{tabular}{|c|c|c|}
\hline & EF-L $(E F 1,2,5,6)$ & EF-H $(\mathrm{EF} 3,4)$ \\
\hline \multicolumn{3}{|c|}{ STRAND } \\
\hline Diameter $(\mathrm{mm})$ & \multicolumn{2}{|c|}{0.829} \\
\hline Filament diameter $(\mu \mathrm{m})$ & \multicolumn{2}{|c|}{$<12$} \\
\hline NonSC : SC ratio & \multicolumn{2}{|c|}{2.3} \\
\hline $\mathrm{I}_{\mathrm{C}}(4.2 \mathrm{~K}, 5 \mathrm{~T})(\mathrm{A})$ & \multicolumn{2}{|c|}{450} \\
\hline Resistive barrier & \multicolumn{2}{|c|}{ Ni coating } \\
\hline \multicolumn{3}{|c|}{ CONDUCTOR } \\
\hline Cable dimensions $(\mathrm{mm})$ & $19.1 \times 19.1$ & $21.8 \times 21.8$ \\
\hline Cabling stages sequence & $(2 \mathrm{SC}+1 \mathrm{Cu}) \times 3 \times 6 \times 6$ & $3 \times 5 \times 5 \times 6$ \\
\hline Number of SC strands & 216 & 450 \\
\hline Number of $\mathrm{Cu}$ strands & 108 & 0 \\
\hline Internal spiral & \multicolumn{2}{|c|}{ yes } \\
\hline Jacket thickness (mm) & \multicolumn{2}{|c|}{3} \\
\hline Jacket material & \multicolumn{2}{|c|}{ SS316L } \\
\hline Void fraction & \multicolumn{2}{|c|}{$\sim 34 \%$} \\
\hline Cross-section & & \\
\hline
\end{tabular}

( $\mathrm{T}_{\mathrm{CS}}$ close to $6.2 \pm 0.04 \mathrm{~K}$ ). Besides, the possible degradation deriving from the different manufacturing stages (compaction, central spiral, etc...) could be evaluated around $0.1 \mathrm{~K}$.

All those results finally validated the EF-H conductor design, which was then driven to mass production phase, actually in progress [23]. Another experimental campaign analysis was dedicated to transient conditions [24] and assessed that a sufficient minimum quench energy margin (MQE) was available in operation.

A second sample was tested, relevant to the EF electrical connection, which design can be seen in [25]. The experimental campaign results showed an average resistance of $2.8 \mathrm{n} \Omega$, and dedicated analyses ([25]) also identified current distribution unbalance as a possible issue in the EF coils.

In addition to the above mentioned samples testing campaigns, the experimental approach dedicated to EF coils is to be further investigated with tests associated to samples extracted from EF-H and EF-L conductor production, tested in transient regime [26].

\section{CS Magnet System}

The CS magnet system aims at providing the flux needed to reach the first stage of plasma current drive and heating. The CS system includes four solenoids stacked as shown in Fig. 1.

The coils are electrically independent to ensure a maximum flexibility to plasma-shape control. The whole system is attached to the TF magnets by structural links located at the bottom of the assembled system (see Fig. 6). A detailed description of the concept can be seen in [18].

\section{A. Mechanical Approach}

Regarding mechanical safety margins investigations, no experimental check was led so far. However, in-depth analyses

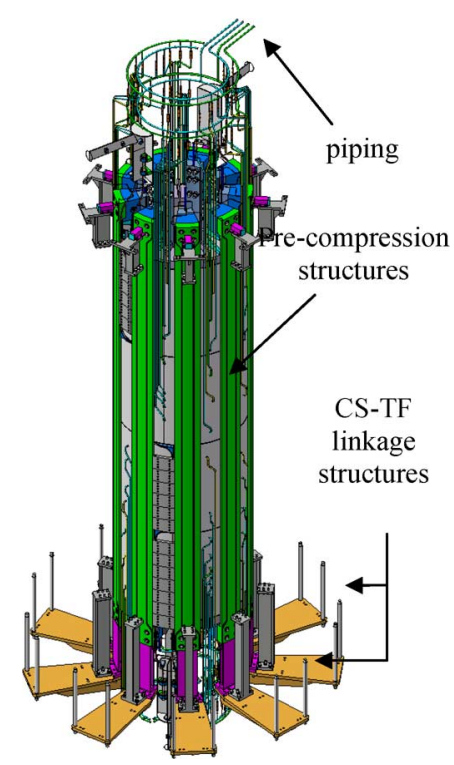

Fig. 6. 3D view of CS system. Attachment structures to TF can be seen in the bottom area.

TABLE VI

JT-60SA CS CONDUCTOR AND STRAND FEATURES

\begin{tabular}{|c|c|c|}
\hline \multicolumn{3}{|c|}{ STRAND } \\
\hline material type & & $\mathrm{Nb}_{3} \mathrm{Sn}$ \\
\hline Diameter (mm) & & 0.82 \\
\hline Non SC : SC ratio & & 1 \\
\hline Resistive barrier & & Cr plating \\
\hline \multicolumn{3}{|c|}{ CONDUCTOR } \\
\hline Operation current (kA) & & 20 \\
\hline Maximum field (T) & & 8.9 \\
\hline Cable diameter (mm) & & 21 \\
\hline Cable pattern & & $(2 \mathrm{SC}+1 \mathrm{Cu}) \times 3 \times 6 \times 6$ \\
\hline Jacket dimensions (mm) & & $27.9 \times 27.9$ \\
\hline Jacket material & & SS316LN \\
\hline Twist pitch sequence & & modified $316 \mathrm{~L}$ \\
\hline Void fraction & & $\sim 33 \%$ \\
\hline Cross section & & \\
\hline
\end{tabular}

were recently performed [18]. Furthermore, new checks are foreseen with latest refined design.

\section{B. Electromagnetic and Thermodynamic Approach}

The CS conductor is made of $\mathrm{Nb}_{3} \mathrm{Sn}$ due to operation conditions: combined middle-range maximum field required by plasma scenarios and a temperature around $5 \mathrm{~K}$. The basic conductor features and operation parameters can be seen in Table VI. As regards the experimental approach, full-size short lengths were recently produced for production qualification [23] that can be used for electromagnetic samples, similarly as for EF samples. The measurements of prototypes performances will be conducted at NIFS facility in early 2011. 


\section{CONCLUSION}

The most recent design of the three magnet systems of JT-60SA were described and an overview of the associated design work was shown. Together with most recent design updates, the main experimental activities driven during the detailed design phase to consolidate the transition towards realization phase were described for each system.

For the TF magnet system, three main issues were experimentally investigated either in mechanical domain (helium inlets) or in cryomagnetic domain (conductor, connection). The testing campaigns of prototypes brought satisfactory results allowing a confident switching to industrial production during which other samples will be tested.

For the EF magnets, electrical issues were addressed regarding conductor and joint for $\mathrm{EF}-\mathrm{H}$, consolidating the conductor design and having joint issues identified. Forthcoming tests associated with EF-H production conductor and EF-L prototype conductor were also evoked.

For the CS magnets, no experimental test was driven, but material for it is available from first conductors production.

Globally, the experimental approach has been mainly advanced in the cryomagnetic domain with a total of five samples, but is not yet completed as production conductor samples benchmark remains ahead (except for one EF-type conductor). Regarding mechanical grounds, tests are foreseen to be led when getting nearer to the production.

As a conclusion it can be stated that the detailed design phase of the three JT-60SA magnetic systems have reached its final stage, each of them including dedicated design validations encompassing — when possible — relevant prototypes tests. It will progressively decrease in amplitude to let place to the realization phase, in accordance with production schedule.

\section{REFERENCES}

[1] H. Tamai et al., "Prospective performances in JT-60SA towards the ITER and DEMO relevant plasmas," Fus. Eng. Des., vol. 82, no. 5-14, p. 541, 2007.

[2] M. Matsukawa, "JT-60SC Design Team, Design and R\&D issues for the JT-60 modification to a full superconducting tokamak," Fus. Eng. Des., vol. 63-64, pp. 519-529, 2002.

[3] H. Tamai, M. Akiba, H. Azechi, T. Fujita, K. Hamamatsu, and H. Hashizume et al., "Design study of National Centralized Tokamak facility for the demonstration of steady state high-plasma operation," Nucl. Fus., vol. 45, pp. 1676-1683, 2005.

[4] M. Kikuchi, H. Tamai, M. Matsukawa, T. Fujita, Y. Takase, and S. Sakurai et al., "Overview of the national centralized tokamak programme," Nucl. Fus., vol. 46, pp. S29-S38, 2006.

[5] K. Tsuchiya, K. Kizu, T. Ando, H. Tamai, and M. Matsukawa, "Design of the superconducting coil system in JT-60SA," Fus. Eng. Des., vol. 82, pp. 1519-1525, 2007.

[6] K. Yoshida et al., "Conceptual design of superconducting magnet system for JT-60SA," IEEE Trans. Appl. Supercond., vol. 18, no. 2, p. 441,2008

[7] P. Barabaschi, JT-60SA Device Design Revision Aimed to Reduction of TF Magnet Cost V6.0, F4E report BA STP PC 02-7.2, 2008.
[8] V. Tomarchio et al., "Design of the JT-60SA superconducting toroidal field magnet," IEEE Trans. Appl. Supercond., vol. 20, no. 3, p. 572, 2010.

[9] M. Nannini, C. Portafaix, P. Decool, N. Dolgetta, L. Zani, and P. Barabaschi, "Mechanical analysis of the JT-60SA TF coils," IEEE Trans. Appl. Supercond., vol. 20, no. 3, p. 521, 2010.

[10] J.-L. Marechal, Note CEA/AIM/NTT-2010.013, 2010.

[11] L. Zani, P. Barabaschi, P. Bruzzone, D. Ciazynski, P. Decool, B. Lacroix, M. Nannini, B. Stepanov, A. Torre, and J.-M. Verger, "Tests and analyses of two TF conductor prototypes for JT-60SA," IEEE Trans. Appl. Supercond., vol. 20, no. 3, p. 451, 2010.

[12] L. Muzzi, V. Corato, G. De Marzi, A. Di Zenobio, C. F. Zignani, L. Reccia, S. Turtu, A. della Corte, P. Barabaschi, M. Peyrot, P. Bruzzone, and B. Stepanov, "The JT-60SA toroidal field conductor reference sample: Manufacturing and test results," IEEE Trans. Appl. Supercond., vol. 20, no. 3, p. 442, 2010.

[13] C. Portafaix, P. Barabaschi, F. Gauthier, P. Hertout, B. Lacroix, J. O. Lesage, S. Nicollet, L. Zani, and R. Villari, "Development of the pseudo 3D thermo hydraulic tool TACOS: Application to JT-60SA TF coils design optimisation," IEEE Trans. Appl. Supercond., vol. 20, no. 3, p. 1794, 2010.

[14] S. Nicollet, B. Lacroix, P. Hertout, and L. Zani, "Development of an extended thermohydraulic simulation tool for fusion magnet design study-Application to the initial versions of JT-60SA TF coils layout-," Cryogenics, vol. 50, pp. 18-27, 2010.

[15] G. M. Polli, L. Reccia, A. Cucchiaro, A. della Corte, A. Di Zenobio, L. Muzzi, A. Pizzuto, G. Ramogida, S. Turtú, R. Villari, M. Nannini, C. Portafaix, L. Zani, and P. Barabaschi, "2D thermal analysis for heat transfer from casing to winding pack in JT-60SA TF coils," Fus. Eng. Des., vol. 84, no. 7-11, p. 1531, 2009.

[16] B. Lacroix, C. Portafaix, P. Hertout, S. Nicollet, L. Zani, P. Barabaschi, and R. Villari, "Thermohydraulic analyses associated with the design of JT-60SA TF coils development and validation of TACOS/TEXTO tool," Adv. in Cryo. Engin., vol. 1218, AIP Conference Proceedings, pp. 471-479, 2010.

[17] A. Di Zenobio, U. Besi Vetrella, V. Corato, A. della Corte, G. Giorgi, F. Maierna, G. Messina, L. Muzzi, and S. Turt, "Application of the ENEA joint concept to NbTi CIC conductors," IEEE Trans. Appl. Supercond., vol. 20, no. 3, p. 1544, 2010.

[18] K. Tsuchiya, K. Kizu, H. Murakami, S. Asakawa, M. Kuramochi, K. Yoshida, and V. Tomarchio, "Recent progress of the design activity for the poloidal field coil system in JT-60SA," IEEE Trans. Appl. Supercond., vol. 20, no. 3, p. 525, 2010.

[19] K. Tsuchiya, Y. Suzuki, K. Kizu, K. Yoshida, H. Tamai, M. Matsukawa, N. Dolgetta, C. Portafaix, L. Zani, and A. Pizzuto, "Mechanical design of JT-60SA magnet system," IEEE Trans. Appl. Supercond., vol. 18 , no. 2, p. 208, 2008.

[20] K. Tsuchiya, "Design change of EF1 support and its related modifications," presented at the TCM8 Meeting, Frascati, 2010

[21] K. Kizu, K. Tsuchiya, T. Obana, and K. Takahata et al., "Critical current measurement of prototype NbTi cable-in-conduit conductor for JT-60SA," Fus. Eng. Des., vol. 84, pp. 1058-1062, 2009.

[22] T. Obana, K. Takahata, and S. Hamaguchi et al., "Upgrading the NIFS superconductor test facility for JT-60SA cable-in-conduit conductors," Fus. Eng. Des., vol. 84, pp. 1442-1445, 2009.

[23] K. Kizu, K. Tsuchiya, and Y. Kashiwa et al., "Construction of the jacketing facility and first production results of superconductor for JT-60SA," IEEE Trans. Appl. Supercond., vol. 20, no. 3, p. 538, 2010.

[24] H. Murakami, T. Ichige, K. Kizu, K. Tsuchiya, K. Yoshida, T. Obana, S. Hamaguchi, K. Takahata, T. Mito, and S. Imagawa, "Stability and quench test for NbTi CIC conductor of JT-60SA equilibrium field coil," IEEE Trans. Appl. Supercond., vol. 20, no. 3, p. 512, 2010.

[25] T. Obana, K. Takahata, T. Mito, S. Imagawa, K. Kizu, H. Murakami, and K. Yoshida, "Magnetic field measurements on a shake-hands lap joint sample of cable-in-conduit conductors for JT-60SA EF coil," IEEE Trans. Appl. Supercond., vol. 20, no. 3, p. 1471, 2010.

[26] H. Murakami, T. Ichige, K. Kizu, K. Tsuchiya, K. Yoshida, T. Obana, S. Hamaguchi, K. Takahata, T. Mito, and S. Imagawa, "Stability margin of NbTi CIC conductor of JT-60SA equilibrium field coil," presented at the ASC 2010 Conference, paper 2LP2C-02. 